Kohl: a Journal for Body and Gender Research

Vol. 6, No. 1 (Summer 2020)

\title{
A Slippery Stage: Tensions and Solidarities in the Cairo Cabaret
}

\author{
Christine Şahin
}

\begin{abstract}
:
This ethnographic case study viscerally explores the micro-level of tactics, tensions, and insights cabaret dancers offer in regard to macro-level gender, class, sexuality, and nationality politics within Cairo, Egypt. As the night wears on in a Pyramid Street cabaret, the dancer's stage becomes increasingly slippery, not just from five-pound notes littered across the dance floor, but from the increasingly volatile intra-MENA male clientele, who contentiously perform their masculinities and nationalist identities through tahayas (greetings) and tipping. As the tipping wars become more heated, the cabaret ra'asa (female dancer), remains the centrifugal force in precariously performing, playing, and being policed by these intersectionally vexed power plays. This case study comes from larger Critical Dance Studies and Middle Eastern Studies ethnographic fieldwork in Cairo; it explores the ways raqs sharqi and other marginalized moving bodies engage with slippery possibilities despite and amidst the tensions of precarious political and economic transformations Egypt has been experiencing since the 2011 revolution.
\end{abstract}


In the tumultuous aftermath of Egypt's January 25th, 2011 revolution, contemporary Cairo continues to grapple with precarious gender, sexuality, class, and nationality politics. Current concerns include turbulent gender politics, undermined by repressive autocratic regimes, and overlapping and deeply severe economic disparities emanating from Egyptian local, as well as western neoliberalist and Arabian Gulf (khaleegy) oileconomies. In this article, I analyze an ethnographic case study from my fieldwork in Cairo's raqs sharqi scene to gesture towards the complex and embodied ways micro-politics between moving bodies are tethered to macro-level state politics. Critical Dance Studies theory argues that the dancing body is a form of undermined knowledge production and dissemination. Thus, mining the choreographic politics of relationships between moving bodies in time and space may offer insight into the flesh and bones of larger political dynamics, in sinuous ways other approaches may simply scratch the surface of.

As the night wears on in a Pyramid Street cabaret, the dancer's stage becomes increasingly slippery, not just from five-pound notes littered across the dance floor, but from the increasingly volatile intra-MENA male clientele, who contentiously perform their masculinities and nationalist identities through tahayas (greetings) and tipping. As the tipping wars become more heated, the cabaret ra'asa (female dancer), remains the centrifugal force in precariously performing, playing, and being policed by these intersectionally vexed power plays and tensions. Here, I viscerally explore how the various bodies within the cabaret site actively negotiate the increasingly slippery terrain of economics as related to changing classed and gendered notions of masculinity, the female laboring body, the overlapping hegemonies of the local Egyptian economy, as well as Gulf petrodollars tied to the oil industry. These political tensions circulate not only within the cabaret site but within macro-level political systems and structures of Cairo, Egypt, at large.

My focal research question asks, what unique insight and knowledge does a dance-centric lens offer to such macro-level state politics? How can it cultivate sustainable solidarities and movement building amidst and despite dominating structures and sites of tension? I argue that within sites, structures, and systems steeped in hegemonic political tensions, there also exist notions and possibilities of the slippery. Approaching a theory of slipperiness necessitates body-centric frameworks and perspective where these same precarious conditions embody potential for corporeal core strengthening, balance, and non-dominant reliance and solidarities with the other. In other words, within the body's kinesthetic engagement with slippery tensions, there exists a turn towards marginalized yet potential-full directions, moves, mutual dependencies, and solidarities. Amidst the slippery stage and sala (seating area) of the cabaret, the slipperiness within and between tensions reach towards a larger political insight: that multiplicitous and multi-directional ways of being, knowing, and choreographing at a corporeal level must remain core to organizing intersectional and sustainable feminist solidarities and movement-building in contemporary Cairo.

This article will focus on a popular cabaret "hot spot" on Pyramid Street during the "Arab season" frequented by middle to upper class Egyptian and MENA men, although primarily saturated with clientele from the 
Arabian Gulf. ${ }^{1}$ Pyramid Street, or Sharia Haram, was originally built by Khedive Ismael to transport important dignitaries from Cairo for the opening of the Suez Canal in 1869. The first two elite casinos with raqs sharqi, Oberge and Shalimar, opened on the street when these sites were visited by the upper crust of local and international guests to see star dancers. During Nasser's era, the street became the bustling residential and commercial area it remains to this day. Particularly during Sadat's era and the Arabian Gulf oil boom, and continuing with the steep economic decline in Mubarak's era, the cabarets on Pyramid Street drastically changed to become focused around the pinnacle objective of getting clients to throw money showers as tipping, known as nuq'ta or keet. Since this time, the cabarets have been characterized by the nimar system, where multiple dancers perform a thirty-minute or so nimra (performance number) in one costume before a brief transition and then the next dancer circulates in for her show. Often a handful of dancers can be seen performing throughout the night and making their rounds up and down the street.

The thirty-minute or so nimra may start with a mejance (raqs sharqi entrance song) but afterwards, the dancer must improvise according to the requests of the moneyed patrons and singer. Often, the music is dominated by Egyptian shaabi (working-class originating popular music), where mawal is quite popular, as well as khaleegy, with a smattering of other requests from Um Kulthum classics to Lebanese debke 3 depending on the biggest-tipping clientele of the evening. The dancer doesn't know what will be played next. Sometimes dancers spend twenty-five minutes of their total show dancing one khaleegy song after another. With the exception of star cabaret performers, the majority of dancers work with a house band that is paid and hired by the venue. Between nimar, the stage is swarmed with other dancing bodies, from male clientele and frame drum players to Egyptian female "hostesses," paid to look pretty, entertain male clientele, and socially dance in the venue. These women can be paid to sit with men at their table and entertain them, and some of them are or may be engaging in sex work. ${ }^{4}$

Another key characteristic of cabaret performances is the constant interruption of the music, singing, and show for the tahaya. A tahaya, or greeting, is when the singer abruptly cuts off the show to say the name, region (country or neighborhood), and sometimes occupation of a client in the microphone. This greeting is done to show his importance to the rest of the venue, as well as simultaneously get him to cough up more tip money. Colloquially, this is akin to a "pay-to-play" "shout out." Often, while the greeting is being pronounced, the singer or client will be throwing, raining, or holding up and wagging keet for all to witness. This tahaya works to encourage the masculinity-fueled tipping competitions that are a primary objective of cabarets. For example, if one man's name and country are being praised, it challenges another man to show his importance and wealth as well. Nationality also is tied up in these equations as clients from the same

\footnotetext{
1 "Arab season" is colloquially known as the time when Arabs visit or vacation in Cairo during summer months when temperatures are more merciful in Cairo than the khaleeg, and cost of living is substantially cheaper while offering an array of culturally familiar yet unique tourism opportunities.

${ }^{2} \mathrm{~A}$ mawaal is a genre of Arabic music that demonstrates strong vocal abilities and improvisational skills. The mawaal occurs before the actual song and relates to poetry traditions wherein the lyrics may have deep meanings that audiences can mutually relate to.

${ }^{3}$ Debke is a popular social line-dancing music from the Levantine regions of the Middle East.

${ }^{4}$ While sex work is a broad term including entertainment, here I refer specifically to direct sexual acts paid for by clients.
} 
country like to see their nation upheld as the most prominent or generous, while other nationalities may enter into the competition to stake a claim in being recognized. These competitions can be invigorated with generosity as well, as clients may dedicate tahayas to one another, and often generosity and personalized importance are the smoke screens the gendered-economic and nationalists rivalries operate within and under. $^{5}$

Cabarets are one of the original sites for housing raqs sharqi within Cairo, though their reputations have made a one-eighty turn from the monarchy era of being decadent sites for the upper crusts of celebrities, dignitaries, and even King Farouk to see the top star performers in the MENA world. Since the economic decline of the Mubarak era, cabarets still have hierarchies from "low-high," but overall, all cabarets are considered by those within the dance industry as the "seediest" of sites where men go to drink, get high, and watch women's bodies. ${ }^{6}$ Yet, cabarets are one of the venues that largely carried on in the immediate aftermath of the 2011 revolution when many boat cruises and hotels completely shut down or drastically cut their number of shows and sails. ${ }^{7}$ Thus, it would seem these ferocious "tipping war" schemes vicariously tied to men's sense of masculinity offers a successful and sustainable system. Seated in the cabaret, watching Egyptian Pounds fly around the room and be continually "scooped up" by youthful Egyptian male tip collectors, as busy plowing the notes together as if snow plows amid a wintry storm, it would appear so. The dynamics of the cabaret system, with its primary focus on men, masculine competition, and the intense value pitted upon the thickness of one's wallet, bore strikingly similar parallels with the primary focus and objective of President Sisi's government. Here, intense concentration was also pitted on the masculine projects of national security and the economy as the primary path to Egypt's successful sustainability. Simultaneously, the intense number of cross-armed and suited Egyptian male bodies staggered throughout the venue, there to keep a watchful eye and a policing presence over the flow of the keet, also reinforced the methods and values of the continuing masculinized and military autocratic regime under Sisi - uni-directional, top-down, linear, and tightly-controlled.

But as a feminist dance ethnographer, I must ask, is there more to the cabaret circuitries than dominant understandings and bodies? What, or whom, is keeping the keet circulating? Are there other ways of being,

\footnotetext{
5 Tracing the roots and routes of this site-specific tipping practice gestures to the entanglements of local Egyptian, intra-MENA, and global forces. Guests provided nu'qta at local shaabi wedding parties in Cairo, with the singer playing the role of nabatshi (the one who collects the tipping and praises/announces the tippers). It also intersects with the MENA oil boom and open-door economic policies of Sadat's era that resulted in the sudden proliferation of the wealthy MENA male clientele within these clubs that started throwing and showering the money.

6 This combination of "drinking, drugs, and revealed female bodies" was consistently cited to me by Egyptian friends and colleagues in the dance industry as reasons for the "seediness" or "lack of artistry" in cabarets. This particularly "low" ranking of cabarets upon the already stigmatized dance work hierarchy is contrasted with other raqs sharqi dance sites such as cruising ships, hotels, and discos.

7 This is not to say that Pyramid Street cabarets had "smooth sailing" in the wake of the 2011 revolution. Throughout their history, cabarets have been targeted by certain sectors of society as being sites of decadent corruption and/or moral depravity. A handful of cabarets were looted and vandalized after the revolution. Many Egyptians reported it was common "street thugs" while others contended it was likely Brotherhood extremists. However, some cabarets did shut down, the reason possibly being tied to new strategies of erasing their "corrupt mark" on society.
} 
knowing, and moving circulating within the cabaret? Oral historian Sayyad Henkesh explained to me that there was a time when all the tipping money in cabarets was real. A client came in with one-hundred pounds and threw one-hundred pounds. However, after some time the system changed, and cabarets used fake notes, or primarily, used a strategic "purchasable ploy" to further amp up and hasten the tipping wars in ways that unevenly benefited clientele already perceived as more financially well-off. ${ }^{8}$ In other words, real money's "exchange value" was dependent upon further reifying already drastically uneven intra-MENA global capitalist flows. For example, an Egyptian client would give one hundred pounds and be given five hundred to throw, whereas a well-dressed Gulf client would give the same amount, of one hundred pounds, and be given two thousand to throw in exchange. Moving forward with this understanding, it points out how the seemingly "sustainable" system is a façade in significant ways.

Further, the tipping used to be split three ways: house, dancer, and band, but since the Mubarak era, all the tipping almost exclusively goes to the house. Thus, the competitive tipping war scheme that has become the main objective in cabarets is ultimately not a sustainable system. Further, it is a system that is becoming increasingly and particularly precarious for the more marginalized Egyptian cabaret laborers, in ways that parallel how gender and lived-reality blind state economic policies also peripheralize these same subjectivities, (such as the working-class, youth, and women). Likewise, this knowledge gestures towards the necessity of looking deeper, from more perspectives and positionalities, to get richer understandings, and thus more nuanced tactics, for creating better equity and more sustainable worlds, at both the micro-level of the cabaret as well as the macro-level of the national economy and gender dynamics.

\section{Narrative Structure and Methodology}

This article hinges upon interwoven theoretical and methodological approaches across disciplines. Theories and methods from Middle Eastern Gender and Sexuality Studies, Dance Studies, ethnography, and choreographic writing whirl together into an interlocking embrace in this work. I approach this research through nuanced dance-centric analysis and sensitively attuned visceral and choreographic writing that embodies Cairo raqs sharqi's site-specific style, structure, and semiotics. My research methodology consists primarily of participant-observation fieldwork at an array of class-stratified performance venues, with a Dance Studies focus on choreographic analysis within these field sites. I use the term choreography in reference to the foundational relationships between bodies, movement, time, and space. I consider choreography as a larger event inclusive of all the bodies within the dance site, analyzing not just the dancers on stages across

\footnotetext{
8 I talked with Sayyad Henkesh and several cabaret managers about tipping practices and history, though Sayyad was the best versed in the history. I interviewed Sayyad Henkesh several times throughout my fieldwork at open coffee shops with our mutual trusted and generous friend Khaled Mansour translating (Aug 2015, Aug. 2016, and March 2017). Sayyad Henkesh is an oral historian from a famous Mohamed Ali Street musician family. The primary way tipping works is that clients pay a set amount such as 100 Egyptian pounds, and depending on their perceived class status, personality, and street smarts, are given multiplied amounts in return. Managers mentioned that it is never a fair "pay-to-play" scheme, but that they try and be clever through the uneven distribution of money to amplify already prominent clientele's status and enjoyment within the venue which they feel, overall, is a successful business model.
} 
Cairo but also the movements, interactions, and connections between audiences, musicians, waitstaff, and hostesses. I focus on how power circulates between all such entities, with each being sources of power, although the extent of which is fluidly determined depending on context and interaction. Additionally, I conduct informal interviews with professional dancers, audience members, managers, musicians, and others involved with the dance industry at large.

In theorizing Middle Eastern feminist methodologies, both Lila Abu-Lughod and Sherine Hafez remind researchers to avoid the seductive romance of resistance. They argue that sharing a complex, intersectional, and visceral story holds more integrity and grit than crafting a happy ending superficially suited to progressive politics (Abu-Lughod, Re-Making Women, 1998; Veiled Sentiments, 1999; Hafez, "Bodies That Protest," 2014' "No Longer a Bargain," 2014). They also gesture to the importance of richly complex ground-level investigations that explore the lived-realities of research subjects, with Hafez noting the undermined yet critical significance of corporeality in such realities as paramount $(2014,173)$. This is particularly important in studies of dance, as dance is often taken up by the general public as a liberational trope. Here, dance is understood as power, a power that can be wielded in enabling and hindering ways, often simultaneously.

To mine the semiotics of this site in ways that embody the contours of the cabaret entertainment system, this article is choreographically structured by a nimra with performatively interspersed tahayas. Critical Dance Studies asserts that the dancing body is producing its own discourse. Therefore, it is incredibly enabling if the dance scholar is able to apply their dance form's choreographic structure and aesthetics onto their research, fieldwork, and writing frameworks. This approach reaches towards a more richly nuanced dancecentric analysis that embodies the insight of site-specific cabaret raqs sharqi, while also grappling with my own positionality politics to the research and writing as a US-located agnibiya (female foreigner) practitionerethnographer, with the aim of centering Cairo stories and subjectivities.

While the investigation focuses on choreographic analysis of the variety of bodies that take to the stage, the writing, like the cabaret show, is constantly interspersed and paused for tahayas. While cabaret greetings focus on keeping money flowing, they do so by calling public attention to "bodies that matter" within the cabaret. However, in this article, bodies that matter are not valued due to their monetary richness, but rather, for their wealth of wisdom. Therefore, interview excerpts from a vast array of peripheralized cabaret characters are inserted within the writing, adding performative pauses to the choreographic commotion. ${ }^{9}$

Where am I as agnibiya practitioner-ethnographer in the particularly situated cabaret performance case study to follow? Having a seat in the back corner of the cabaret. Although a professional performing and teaching soloist in the US, where I was used to taking up the spotlight or being "center staged," my identity as a dancer took a different turn to do my research with integrity in Cairo contexts. There, my research aims of centering

${ }^{9}$ To maintain the power and performative effect of the tahaya pauses and proclamations, the details surrounding how I met and interviewed dancers are included within footnotes after each quote, rather than more "smoothly" fitting into the body of the text. My objective with this performative choreographic writing is for the reader to get a sense of the power and punctuation leading to greater attention and focus on the insight that cabaret workers shared with me in ways that embody the cabaret performance system. 
Cairo subjectivities and stories methodologically necessitated taking a back seat. I sat in the back corner of cabarets throughout Pyramid Street many nights between 2016-2019 after getting permission from the venue staff, management, and dancers to do participant-observation dance fieldwork. This too elicited many tensions. For example, I was sometimes turned away at the door, with staff concerned that I was some kind of undercover agent for the Egyptian police or government. I always respected this decision, but when granted entrance to watch and briefly and informally interview dancers between their nimar, I would take a seat with my accompanying Egyptian male colleague (who felt it necessary to accompany a young solo woman to such places for safety and respectability) in the back corner of the cabaret. My back seat positionality allowed me to observe and let other dance and non-dance bodies take center-stage.

\section{Case Study: A Night in the Cairo Cabaret}

An explosion of sensory stimuli crashed over my body like a tidal wave, from the pulsating, percussion-heavy shaabi music thumping in my heart, to the dense layer of shisha, cigarette, and hashish smoke, to the multicolored flashing lights dashing across the venue. Bodies and movement assaulted the vision from every direction. The singer sung on stage with male drummers, overly attentive waiters stood tableside, and youthful working women were planted strategically throughout the venue. Of course, this is all not to forget the actual paper money sporadically exploding into the air here and there as if confetti being tossed on New Year's Eve. This money often littered across the seating area and stage, making an increasingly slippery terrain for the female dancer to negotiate, both physically in regards to slippages during a dance step on the layer of loose paper notes, as well as ideologically, in regards to the political tensions of nationality, gender, sexuality, and class.

Finally, there were those bodies that were contradictorily most invisiblized within the space, despite their most pervasive, and invasive, physical presence - crawling, running, crouching, and clambering around the stage, sala (seating area), and within and amidst the table and chair legs beneath and around all of our feet. These almost exclusively young Egyptian men were quick and constantly exerting robust physical labor winding throughout the mass of feet, table and leg chairs, and delicate shishas as if competing in a timed obstacle course. Their sole job was to collect the tip money (keet) as rapidly as possible from the floors, stage, and tables to ensure the tip money was ready to be re-circulated. ${ }^{1}$ However, their labor was also to ensure the keet was staying in circulation and not being taken by any number of the bodies that could potentially tuck away a few notes. If the known amount of total keet was less than what the cabaret management had originally counted to begin the night with, it was these young men that would take the fall, and by their frantic and grueling physical labor, this looming consequence seemed severe.

Despite the male youth's intense physical proximity to patrons, they were almost entirely ignored. This in/visibility contradiction gestures towards their low status on the hierarchy of bodies within the site. Their

1 Nuq'ta is the singular colloquial Arabic, and keet the plural, for the specific kind of tipping money circulated within cabarets. 
choreographies within the cabaret not only mirrored but slipped into a hypervisibility of the gendered labor and economic conditions of Egyptian male youth at large, both pre and post-revolution. Male youth scrambled for fewer and scarcer employment opportunities that mostly had a glass ceiling already based on one's socioeconomic background. There structurally weren't opportunities to continue to move up if you simply "worked hard." Yet, working hard was the only way to survive with increasing inflation of basic goods and foodstuff. These young men labored intensively to keep the keet off the floor, just to have it placed back into the already wealthy hands of those who would simply re-toss it. Within the dire economy and greater patriarchal norms, these youths found themselves at the bottom of the pile of those which benefitted the least from these systems, alongside the working-class women. Yet, these same structures demanded their physically exhausting and increasingly resourceful labor, but also the greatest potential for policing and punishment amongst such tensions.

Julia sultrily strutted onto the stage to start the next nimra. ${ }^{1}$ A few of the hostesses stepped down after Julia started her show, but a few stayed on stage and swayed their hips to the music. Julia was of a darker olive skin tone and extremely tall, her spike heels giving her even more of a towering presence. She wore a midrange bright red bra and a tight mermaid-skirt costume, but without any costly jewelry accessories that helped give the image of star-status, just a wristwatch. However, what Julia had invested in were extravagant breast enhancements, all the more advertised through her teensy costume bra that her very full breast tissue was strategically spilling out of.

One Saudi man was particularly taken by Julia's allure and scrambled onto the stage to dance with her while the singer was off giving a tahaya to a table of businessmen visiting from Upper Egypt. He had a hungry look in his eyes as he stared at Julia's breasts, not even breaking his greedy stare as he pulled out a couple hundred-pound Egyptian notes from his wallet. Julia sensed the precarity in his hungry gawking and started looking around for the singer to help control the situation, but he was across the stage and the Saudi man was now only a foot from her body. Julia smiled at him and bounced her breasts percussively as she reached out to hold both his hands and socially dance. The client seemed hypnotized as he kept his stare but locked his hands in hers. Though he pressed his body towards hers, she used her outstretched arms as a barrier to keep him from touching her, and again looked over for her singer's assistance.

As a female practitioner myself, I empathized with Julia, recognizing her arm framing as a tactic dancers all over use to quickly dissipate a body tipping situation that crosses our personal body boundaries. Here, however, it was not necessarily just the dancer's boundaries, but the state's. Cabarets are one of the most notoriously policed venues. If the dancer steps off the stage, accepts body tipping, or is caught without wearing long enough undershorts or shabaka (belly cover) she can be heavily fined or jailed. Yet, the men that crossed onto the stage's boundaries and attempted to touch dancers or purchase women's company

1 Julia is a pseudonym to protect the anonymity of the dancer. Julia was originally from Alexandria but moved to Cairo a few years ago for the greater financial opportunities and potential social mobility of working in the Cairo cabaret circuits. She was a featured performer at this particular cabaret but did not have time to stay between her nimar at various cabarets for more than brief introductions. She verbally consented to me writing about her performance. 
were not under such policing precarity and pressure. Tahaya Donya, a cabaret hostess. "I hate that all people think they can have sex with me and that I am such a bad person. The blame is always cast upon me like I am the reason these places are shameful. But why don't the people ever think to point their fingers at these drunk vulgar men that come here?! I'm divorced and raising my girls alone, but these men?! They have wives, children, and they come here and spend all the family money." 1

As Donya points out, the working women within find their bodies bearing heavy weights not only to survive, but to try and gain financial capital while negotiating the sexually suspect criminality burdened upon their bodies. At the same time, these bodies also find ways to creatively capitalize within the space using their corporeality, as Julia's extended arm work highlights. Within Dance Studies, corporeality is a theorization relating to the lived reality of embodied experience. In other words, the body is set in culture, wherein the body is understood with agency while also already interpolated by larger systems of power. ${ }^{1}$ Tahaya Bossy, cabaret dancer. "Of all venues, cabarets are the most difficult, because you can get bad men that cross the line and want to touch you in a sexual way. The security in the cabaret is not the best either, because so much is happening and the staff cares mostly about keeping the money moving above all else. So, in these situations, if I can't take my protection from the management I have to take my power myself. I take my power from my charisma and clever moves. If they get too close I have to keep them happy and act like l'm happy too, but really, I'm using the way I dance with them to keep the line from being crossed." 1

While Bossy and Julia both expect the male management to offer protection in the cabaret system, mirroring the patriarchal gender system at large and what assistance it ought to provide, when it is not offered they do not stand by idly or passively. Rather, they take matters into their own hands through slyly slipping into corporealized cocktails of clever charisma and covertly coded choreographies to maintain core strength and balance amidst more dominant tensions.

The singer and an accompanying duff (frame drum) player had made their way over to the Saudi man to encourage his tipping, though Julia had already initiated that work. The Saudi turned and violently threw a

\footnotetext{
1 I held a quick and informal 10-minute interview with hostess 2 Donya during one of her shifts at a cabaret on July 20 , 2016. The ten-minute interview actually consisted of quick 1-2 minute questions and answers over a period of breaks when she came to check on our table as she was busy working and attending to many customers. I paid her 50 pounds for the interview and my Egyptian male colleague helped with translating. Because this interview occurred in the noisy cabaret table-side we also recorded the interview and later translated it again into an English recording on our drive home. I later transcribed it by myself in the U.S. Interviewing hostesses within cabarets were some of the hardest interviews to procure as several women did not give us permission to ask questions, and other times the management would not allow it. In this case, Donya granted us permission, but made sure it was okay with the management as well. Many cabaret staff workers were concerned I was working for the local Egyptian police or government and were concerned I would only want to report negative things about their work. Every time we did procure cabaret interviews, we were also invited at some point into the manager's office to talk about my research.

1 Please see pioneering dance scholar Susan Foster's editedªnthology Corporealities: Dancing Knowledge, Culture, and Power (1996) for more on the understanding of corporeality as a Dance Studies theory.

1 I held a quick fifteen-minute informal interview with Bossy on Aug 10, 2016 after her nimra in a small alley outside the cabaret. My male Egyptian colleague was assisting with translating and her manager/husband was also present. I recorded the interview and transcribed it myself back in the U.S.
} 
stack of notes at the singer, rubber band still attached, so it threw all together as a projectile brick of money. The man started chucking hunks of bounded notes at the duff player and singer, and Julia backed up to give more room between herself and the client whose drunken stupor was turning aggressive. Two of the managers made their way over to the hubbub to help control the situation, showing I was not the only one fretting over the increasing tension. However, for the management, keeping the keet in motion remained the primary ultimatum, as opposed to concern for the workers, despite the man's aggression.

Julia interjected in the bubbling tension of the man's aggression by performing a deep backbend in front of him, ending with her breasts erect and directly under his gaze as her head hung low and she fervently shook her breasts from side to side. The Saudi relaxed a little, as he began taking great pleasure in holding the stacks of money over her cleavage and letting the notes slowly spill down and bounce off her reverberating chest. Thankfully, her risky move worked to help dissipate the tension, because otherwise, she would have put herself into an extremely vulnerable position, particularly considering his drunken aggression. $\mathrm{He}$ snapped his fingers to have the waiter continually re-supply his extended hand with money stacks to shower down upon her breasts. He cackled with excitement as he towered above Julia and watched the notes glide and bounce off her shaking flesh.

Meanwhile, the waiter scurried back and forth, breathing heavily as he rushed to keep the Saudi's supply stocked. The Saudi did not acknowledge his waiter; he just left his hand upheld and expected it to be continuously resupplied without even looking at, or never the less thanking, the waiter. I felt my stomach churn watching the young waiter rush to do his bidding without any acknowledgment, at the man's entitled cackling, and especially for Julia's core and thigh muscles, that must be burning at this point from sustaining such a labor-intensive pose. I wondered if it was the noxiousness of the toxic capitalist masculinity embodied within this performance that caused my stomach to twist and tie up in knots.

This Saudi man vacationing in a developing country, that significantly depended on his nation for financial aid and migratory work, was exuding pleasure through his objectifying gaze by dumping thousands of pounds, just for show and the performance of power it held, upon a pair of enormous fake breasts. Julia's attentiveness to the man was also not genuine lust or attraction, but part of the show. This type of world, run by virile capitalist-fueled masculinity, in a sense, had to be performed on the stage, for it was constructing worlds that only could exist in fiction. It was a sham charade and not a sustainable system. At the same time, the strained thighs of the working-class dancer, the heaving chest of the young working-class Egyptian waiter, these were the bodies bearing the brunt of the excessive labor to try and keep up this façade. Their labor and exertion were incredibly real. This capitalist masculinity was fueled by the paradigm ideology that one was never enough, in senses of Self that were founded upon loss and deficit. The incessant need to be more, whatever "more" was, existed with an attainable price tag. Problematically, these attainable "mores" could only lead to worlds of fiction and aggressive hierarchal power relationships between bodies. Julia, physically bent over backward to uphold this fictional matrix of power, had cultivated flexibility and sustained strength within this schema, but even strong lean muscles fatigue, strain, or injure after excessive exertion. 
Suddenly, Hamada, the toura finger cymbal player from the band, was quickly dancing over to Julia while rhythmically accenting the music with his cymbals. He caught the eye of a hostess who also began walking over to Julia. They exchanged glances as they melded into Julia's performance. The hostess leaned forward to shimmy her chest above Julia's, meanwhile Hamada kneeled down and clanged his toura to match the shimmying energy of their chests from underneath Julia's bent back. After a moment they all rose up together and began dancing cheekily around the Saudi. The transition kept up the appearances of endless fictional enjoyment for the client, while dissipating both the building aggression, as well as imminent muscle fatigue of Julia's thigh and core muscles. I was awestruck by how smoothly they handled the situation, but just as equally disenchanted by how unrewarded their efforts would be since the tip-sharing stopped. Julia glanced down at her watch; her time was up. She then quickly sprinted off the stage to catch her next nimra at a different cabaret down the street.

\section{Analysis}

Despite the clever coalitions and choreographies performed within the cabaret, the over-all structure steeped in powerful economic hegemonies of local scarcity and transnational dependency cannot be elided. At the same time, the cabaret circuitries offered glimpses of other worlds and ways of being. Here, the densely shared space and dynamically traversable stage and sala of the cabaret, led to circuitries and systems constructed out of other bodily relationalities and values systems. It is this precise diverse density of bodies and how they move within the shared space that allows new circulations, coalitions, and collective possibilities to form in confrontation to the otherwise dominating system. Here, the variously marginalized bodies work better together to capitalize upon their own pleasure, belonging, job security, and dignity. Rather than understanding differences (in class, gender, sexuality, or status) as raw material for constructing isolating and competitively hierarchal dividers, these other networks utilized these differences as valuable foundations to create cohesive and clever coalitions. As Hamada, the hostess, and Julia physically lifted each other up to then dance together, when variously marginalized bodies within the cabaret found themselves "not enough" as the dominant hegemony would have all bodies interpolated, they instead found wholesome recourse in one another. Rather than buy into the schemes of being objects of purchasable pleasure or compete amongst one another for partial doses of spotlight or social capital, these laboring dance bodies found pleasure and profitable maneuvering in their own bodily networks and values of abundance, community, self-trust, and corporealized creativity. As laborers within the cabaret experienced working in the chaos of non-normative directionality, from tip-collecting youth crawling between table legs to dancers holding deep back-bends, these polyvalent bodies found different ways to move through the world. In doing so, as I argue, they capitalized upon an alternative wealth founded within their marginalized yet multiplicitous and multidirectional ways of being, connecting, and moving.

Wherein other professional raqs sharqi sites in Cairo, such as five-star hotels, many dancers reified their social standing by placing deliberate physical, ideological, and bodily divisions between their bodies and those sprawling across this paper's pages, here in the cabaret, different directions are taken. I was reminded of relevant insight from another raqs sharqi performer that I had interviewed earlier in my research, but whose 
words remain critical here. Tahaya Zara, a self-proclaimed "zero-star to five-star" dancer (because she works all class-levels of gigs). "Do you know what l've learned by taking every type of gig? Wealth. What's the point of coming to Egypt and working only in one 'top spot?' Number one, everyone thinks of dancers as sluts, why would I get off on being a five-star slut? Internal self-hating, I think a lot of dancers secretly hate being dancers. Of course, if you are a woman who slut-shames, well. Audre Lorde, she said the true revolution is in facing, I don't know the exact words, but it's basically about getting through the oppression that lives inside you. A lot of dancers have issues with their own art because it's associated with sexuality and prostitution and using your body to make money, and actually, there's nothing wrong with any of that."1

Zara does not just call attention to external physical and ideological divisions as oppressive and limiting. Rather, she specifically highlights the importance of deconstructing the most deeply-held internal divisions we use to define and cultivate our senses of Self. Her powerful statement aligns with Julia, Bossy, and Donya, who also came to trust themselves despite how their labors misaligned with dominant gender, sexuality, and economic norms - norms increasingly precarious and policed within contemporary Cairo. Their experiences gesture towards a more genuine and sustainable wealth and value system founded within kaleidoscopes of colorful and collectively aligned corporealities, rather than the competitive keet and its interlaced tensions strewn across the stage and flying through the air.

This dynamic resonates with theorizations by Middle Eastern political theorist Timothy Mitchell on carbon democracy and Mc Jihad. ${ }^{1}$ In dissecting global capitalism's successful hegemony fhrough oil economies, he discovers that purposeful divisions and separations were the main means by which multinational oil corporations succeeded in controlling uprisings and protests for more democratic rights. Corporations utilize divisions between classes, nationalities, and ethnicities, as well as physical divisions of the processes of production and transportation of oil, to disrupt workers' chances for collective action (2013). Within the microcosm of the cabaret, it is the way marginalized bodies find moments and spaces of slippage through interaction with one another amid the shared stage and sala that the creation, and also vulnerabilities, within

1 I held an informal interview with Egyptian-English dancer Zara and her manager at an open baladi 'ahwa (coffee shop) during a long break between her gigs on Sep. 13, 2017. Zara works in venues across the spectrum (boats, hotels, weddings, cabarets, etc.) and finds a special value in each type of venue, bringing richness to her dance and life experience. The interview was primarily in English and I recorded it and transcribed it myself back in the U.S.

1 Timothy Mitchell's Carbon Democracy argues that fossil fiels create both the opportunities for forms of modern democracy as well as their limits. This carbon-democracy is a global process wherein one country's form of politics is in relationship with various other transnational politics. It is in tracing these connections, pipelines, refineries, histories, shipments, and circulations of oil and money, that Michell is able to offer a more complex and grounded understanding of modern U.S. democracy and how it relates to the autocracies within parts of the Middle East. Mitchell argues that switching to oil-based economies was deliberately tied to controlling people's claims to democracy at home (U.S.A.) but also in key Middle Eastern nations such as Egypt and Saudi Arabia by limiting their ability to produce and control their own oil. McJihad is Mitchell's theory that global capitalism can only function in different localities (such as key oilproducing Middle Eastern countries) by fusing with local social forces and moral authorities. These 'fusings' with local forces and authorities may or may not mesh with global capitalism and empire's methods and goals, and their pairing is often rife with tension and contradiction. He argues that it is within these hybridized local forms of McJihad that people must look for the vulnerabilities and weaknesses within the system, which I apply it at the micro level of the cabaret. 
the localized and hybridized Mc Jihad process are found. Working Egyptian-English dancer Zara pushes on

Mitchell's theory to point out that the core of these divisions, thus the core of vulnerabilities and thus potentiality, lies within corporealities.

\section{Conclusion}

Mining the micro-roots of these processes, and how they are played out across cabaret bodies, illuminates in larger ways how class, gender, sexuality, and nationality as corporealized are at the core of macro-level political and economic tensions affecting Cairo. Julia, Hamada, tip collectors, hostesses, and other laboring bodies within the cabaret worked in slippery yet significant cross-aligned solidarities and creative coalitions that swerved multi-directionally. Thus, their corporealities and choreographies disrupt and re-direct the unidirectional and top-down directionality of power dynamics that both dominant petrodollar fueled heteromasculinities and iron-fisted autocracies, attempt carving into the larger social system and citizen subjectivities. Alternatively, these cabaret workers gesture to the importance of centralizing the ground-level lived realities of an array of marginalized corporealities for sustainable and equitable state-level political insight and tactics. Focusing on insights, cautions, and subtle yet slippery tactics from the cabaret over-all argue that moving forward sustainably, will mean moving together in multiplicity and multi-directionality across corporealities. 
Kohl 6.1

\section{References}

Abu-Lughod, Lila. Re-Making Women: Feminism and Modernity in the Middle East. Princeton: Princeton University Press, 1998.

---. Veiled Sentiments: Honor and Poetry in a Bedouin Society. Berkeley: University of California Press, 1999.

Adum, Priscilla. "Farewell to the Al Ghandoul Nightclub on El Haram Street." Shira.net. Accessed: May 19, 2017. http://www.shira.net/about/el-gandoul-nightclub.htm.

Ahmed (Cabaret Singer). Personal Interview. Apr. 3, 2017. Cabaret in Cairo, Egypt.

Ahmed (Stage Manager). Personal Interview. Apr. 3, 2017. Cabaret in Cairo, Egypt.

Bossy. Personal Interview. Aug. 10, 2016. Cabaret in Cairo, Egypt.

Botman, Selma. Engendering Citizenship in Egypt. New York: Columbia University Press, 1999.

Cabaret Manager (Anonymous). Personal Interview. Mar. 10, 2017. Cabaret in Cairo, Egypt.

Donya. Personal Interview. July 20, 2016. Cabaret in Cairo, Egypt.

Foster, Susan Leigh, editor. Corporealities: Dancing Knowledge, Culture, and Power, London: Routledge 1996.

Gelvin, James. The Modern Middle East, th $^{\text {th }}$ ed. New York: Oxford University Press, 2016.

---. The Arab Uprisings: What Everyone Needs to Know, $2^{\text {nd }}$ ed. New York: Oxford University Press, 2015.

Hafez, Sherine. "Bodies That Protest: The Girl in the Blue Bra, Sexuality, and State Violence in Revolutionary

Egypt." Signs: Journal of Women in Culture and Society, vol. 40, no. 1, pp. 20-28. 2014.

---. "No Longer a Bargain: Women, Masculinity, and the Egyptian Uprising." American Ethnologist, vol. 39, no. 1, pp. 37-42. 2012.

---. "The Revolution shall not pass through Women's Bodies: Egypt, Uprising and Gender Politics." The Journal of North African Studies, vol. 19, no. 2, pp. 172-185. 2014.

Hamada. Personal Interview. Feb. 5, 2017. Cabaret in Cairo, Egypt.

Henkesh, Sayyad. Personal Interview. Aug. 2015, Aug. 2016, and Mar. 2017. Dream Coffee Shop in Cairo, Egypt. Mitchell, Timothy. Carbon Democracy: Political Power in the Age of Oil, London: Verso 2013.

Nieuwkerk, Karin Van. A Trade like Any Other: Female Singers and Dancers in Egypt. Austin: University of Texas Press, 1995.

---. Performing Piety: Singers and Actors in Egypt's Islamic Revival. Austin: University of Texas Press, 2013.

Pratt, Nicola. "Gendered Paradoxes of Egypt's Transition." 50.50. Gender, Sexuality, and Social Justice.

OpenDemocracy.net. Feb. 2, 2015. Accessed: Sep. $5^{\text {th }}, 2016$.

https://www.opendemocracy.net/5050/nicola-pratt/gendered-paradoxes-of-egypts- transition.

Wynn, L.L. Pyramids and Nightclubs: A Travel Ethnography of Arab and Western Imaginations of Egypt, from King Tut and a Colony of Atlantis to Rumors of Sex Orgies, Urban Legends about a Marauding Prince, and Blonde Belly Dancers. Austin: University of Texas Press, 2007.

Zara. Personal Interview. Sep. 13, 2017. Baladi Coffee in Cairo, Egypt. 